\title{
Longitudinal investigation of wandering behavior in department of veterans affairs nursing home care units
}

\author{
Bellinda King-Kallimanis ${ }^{1}$, Lawrence Schonfeld ${ }^{2, \dagger}$, Victor A. Molinari ${ }^{2, \ddagger}$, Donna Algase ${ }^{3}$, Lisa M. Brown ${ }^{2}$, \\ William D. Kearns ${ }^{2}$, Darlene M. Davis ${ }^{4}$, Dennis H. Werner ${ }^{5}$, Elizabeth R. Beattie ${ }^{6}$ and Audrey L. Nelson ${ }^{5}$ \\ ${ }^{1}$ University of Amsterdam, The Netherlands \\ ${ }^{2}$ Department of Aging and Mental Health Disparities, Louis de la Parte Florida Mental Health Institute, University of South Florida, \\ Tampa, FL, USA \\ ${ }^{3}$ School of Nursing, University of Michigan, Ann Arbor, MI, USA \\ ${ }^{4}$ Home Based Primary Care, James A. Haley Veterans Administration Medical Center, Tampa, FL, USA \\ ${ }^{5}$ Patient Safety Center of Inquiry, James A. Haley Veterans Administration Medical Center, Tampa, FL, USA \\ ${ }^{6}$ School of Nursing, Queensland University of Technology, Brisbane, Australia \\ Correspondence to: L. Schonfeld, PhD, E-mail: schonfeld@fmhi.usf.edu \\ ${ }^{\dagger}$ Professor and Chair \\ ${ }^{\ddagger}$ Professor
}

Objectives: To explore the extent of and factors associated with male residents who change wandering status post nursing home admission.

Design: Longitudinal design with secondary data analyses. Admissions over a 4-year period were examined using repeat assessments with the Minimum Data Set (MDS) to formulate a model understanding the development of wandering behavior.

Setting: One hundred thirty-four Veterans Administration (VA) nursing homes throughout the United States.

Participants: Included 6673 residents admitted to VA nursing homes between October 2000 and October 2004.

Measurements: MDS variables (cognitive impairment, mood, behavior problems, activities of daily living and wandering) included ratings recorded at residents' admission to the nursing home and a minimum of two other time points at quarterly intervals.

Results: The majority (86\%) of the sample were classified as non-wanderers at admission and most of these (94\%) remained non-wanderers until discharge or the end of the study. Fifty-one per cent of the wanderers changed status to non-wanderers with $6 \%$ of these residents fluctuating in status more than two times. Admission variables associated with an increased risk of changing status from non-wandering to wandering included older age, greater cognitive impairment, more socially inappropriate behavior, resisting care, easier distractibility, and needing less help with personal hygiene. Requiring assistance with locomotion and having three or more medical comorbidities were associated with a decreased chance of changing from non-wandering to wandering status.

Conclusion: A resident's change from non-wandering to wandering status may reflect an undetected medical event that affects cognition, but spares mobility. Copyright (C) 2009 John Wiley \& Sons, Ltd.

\footnotetext{
Key words: wandering; longitudinal; veterans; nursing homes

History: Received 19 December 2008; Accepted 22 April 2009; Published online 14 July 2009 in Wiley InterScience (www.interscience.wiley.com).

DOI: 10.1002 /gps.2316
}

Although many researchers have proposed diverse definitions of wandering, wandering typically refers to aimless locomotion often occurring with recognizable patterns such as 'pacing' or 'lapping' (Snyder et al.,
1978; Algase, 1999; Algase et al., 2003). Prevalence estimates of wandering range from $10-70 \%$ and depend on the populations and settings studied (Rovner et al., 1986; Dawson and Reid, 1987; Teri 
et al., 1988; Health Care Financing Administration Medicare and Medicaid, 1989; Burns et al., 1990; Nagaratnam et al., 1998; Klein et al., 1999; Kiely et al., 2000; Kopetz et al., 2000). Wandering among residents in nursing homes (NHs) can become a significant behavior problem and safety issue. If a $\mathrm{NH}$ has inadequate risk management planning, wandering may be associated with a variety of negative sequelae including falls, weight loss, fatigue, sleep problems, abuse, getting lost, premature institutionalization, use of restraints, and untimely death (Cancro, 1968; Soverini and Borghesi, 1968; Cumming et al., 1982; Stokes, 1986; Rheaume et al., 1987; Fompa-Loy, 1988; Lam et al., 1989; Moak, 1990; Rockwood et al., 1991; Algase and Struble, 1992; Burton et al., 1992; Vieweg et al., 1995; Algase, 1998; Kopetz et al., 2000). In reviewing legal claims filed against $\mathrm{NHs}$ due to elopement related to wandering, $70 \%$ of the claims were associated with the death of the wanderer (Rodriguez, 1993).

Wandering is not only a potential detriment to the health and well-being of $\mathrm{NH}$ residents, but poses unique problems for nursing caregivers, other residents, and administrators. Wandering can lead to an increase in staff stress levels, in behavior management problems that require extra staff time, and an increase in safety and liability concerns for upper management (Rader, 1987; Kiely et al., 1998; Altus et al., 2000; Colombo et al., 2001; Cesari et al., 2002; Colon-Emeric et al., 2003). Ten per cent of all lawsuits filed against NHs are for liability issues related to the mismanagement of wandering (Foxwell, 1994). Using researchbased preventative strategies, the ability to predict which residents are most at risk for wandering may yield psychological, physical, and financial dividends for residents and staff alike.

A review of the literature suggests that living settings (Hermans et al., 2007), medical conditions and side effects (Desai and Grossberg, 2001), differential reinforcement (Heard and Watson, 1999), caregiver characteristics (Desai and Grossberg, 2001; Ward et al., 2003), and cognitive status may influence wandering behavior. Wandering is common among those with cognitive impairment, particularly for those who have problems with language, memory, orientation, and concentration (Algase, 1992). As many as two-thirds of individuals suffering from dementia may exhibit wandering at some point in the disease process; it occurs more frequently among those with Alzheimer's disease than those with vascular dementia (Cooper and Mungas, 1993; Hope et al., 1994; Thomas, 1997; Heeren et al., 2003). Wandering is associated with non-aggressive agitation (Colombo et al., 2001;
Cohen-Mansfield et al., 1997a), screaming (Snyder et al., 1978a), physical aggression (Dawson and Reid, 1987), and lowered mood (Klein et al., 1999; Kiely et al., 2000). In comparing $\mathrm{NH}$ residents with significant cognitive impairment who do wander to those who do not wander in a VA setting, we found wanderers to have more severe cognitive impairment, socially inappropriate and disruptive behavior, greater mobility, and more dependence in personal hygiene (Snyder et al., 1978). The evidence is conflicted regarding whether wandering is related to gender, with some studies suggesting no difference and others indicating a higher prevalence among males (Kiely et al., 2000; Schonfeld et al., 2007a).

There are few studies that have examined the trajectory of wandering behavior. Longitudinal studies are important in establishing causality because they allow researchers to control for differential cohort effects. Kiely et al. (2000) used baseline and 3-month follow-up Minimum Data Set (MDS) assessments to explore the relationship between resident characteristics and the development of wandering for $8892 \mathrm{NH}$ residents across three states. The authors found that there were certain cognitive (i.e., short- or long-term memory problems), medical (i.e., pneumonia, dementia, constipation), physical (i.e., functional impairment), emotional (i.e., expressions of sadness or pain), and psychopharmacological (i.e., antipsychotic medication usage) variables associated with the development of wandering. The findings of this large sample study are intriguing, but limited by a brief 3-month study period. Hope et al. (2001) investigated the natural history of wandering with a prospective 10-year study. Eighty-six community-dwelling individuals with dementia were administered detailed interviews at 4-month intervals to assess wandering behavior. Onset of wandering was related to changes in cognitive status, but unrelated to gender, age, or time since onset of dementia. This study was limited by the small sample size of those who ultimately engaged in wandering behavior.

The purpose of the current study was to investigate the development of wandering behaviors by analyzing a Veterans Administration (VA) data base of new admissions over a 4 -year period. This data base initially had been utilized to identify the concomitants of wandering behavior noted above, and later to address the problem of wanderers with psychiatric diagnoses but no significant cognitive impairment. More details of the methodology are described in these early papers (Schonfeld et al., 2007a; Belanger et al., 2008; Molinari et al., 2008). This study extends our previous work by using longitudinal data on VA NH residents to assess changes in wandering patterns. 


\section{Methods}

\section{Sample}

The data base includes all MDS assessments administered from 15 October 2000 to 15 October 2004 for all 134 VA NHs. Data used were approved by local institutional and human subject review boards.

According to the 2001 National Survey of Veterans, there are more than 25 million veterans in the US, and approximately $25 \%$ of these utilize the VA system. Demographic trends suggest that the VA is providing care to a rapidly aging population, requiring enhanced geriatric medical services. Accordingly, the prevalence of dementia within this population has grown with increases in wandering behavior and its disruptions. The MDS is part of the Resident Assessment Instrument required for assessment of every $\mathrm{NH}$ resident's functioning, commencing within 14 days of admission and repeated every 3 months or when a temporary discharge was required or there was a major change in resident status. MDS assessment focuses on activities of daily living, cognition, mental status, and physical health. In the MDS procedural manual, wandering is defined as 'locomotion with no discernible, rational purpose,' and is among the behavioral symptoms evaluated.

The current sample comprises residents who:

- Were first-time NH admissions. Individuals were excluded if a previous stay in any type NH was noted on the MDS.

- Were Male. Because female residents constituted fewer than $2 \%$ of the cases, these cases were excluded.

- Had a complete MDS admission assessment (complete basic demographics and key wandering variables in MDS Section E 'Mood and Behavior Patterns').

- Were not in a comatose state.

- Could ambulate freely with or without the aid of an assistive device (i.e., cane or walker) or wheelchair.

- Had at least three MDS evaluations that were not conducted more than 6 months apart or less than 1 month apart.

\section{Data analysis}

To analyze the data we first explored discrete time survival analysis for multiple spells data. However, because so few residents changed status over an extended period of time (the majority who changed status did so early in the assessment), it was not feasible to conduct this analysis. A growth curve analysis with a dichotomous outcome was attempted; however this analysis also was not feasible due to issues with convergence and limited amount of variance. As a result we decided to use descriptive statistics to evaluate time to event and other variables that might be related to change in wandering status. Finally, to investigate admission variables and the impact that they had on wandering status, two multivariate logistic regression models were built, one for wanderers at admission, with the outcome defined as remaining a wanderer versus changing status to a non-wanderer, and the other for non-wanderers at admission, with the outcome defined as remaining a non-wanderer versus changing status to a wanderer. All analyses were conducted using Stata 9.2.

\section{Results}

The sample comprised 6673 VA NH residents. Demographic variables of the sample broken down by wandering classification can be seen in Table 1.

\section{Wanderers at admission}

Of the 933 residents who were classified as wanderers at admission, 49\% remained wanderers for the duration of the study, until discharge or death. Of the $51 \%$ of the residents who changed status, $85 \%$ had one change of status to a non-wanderer. A further $9 \%$ of the group of residents who changed status changed to nonwanderers and then back to being a wanderer. In other words, $94 \%$ of residents who wandered at admission changed wandering status at most two times during the observation period. The remaining $6 \%$ fluctuated in wandering status multiple times during the period observed. The mean number of observations was $6.5(\mathrm{SD}=3.7)$ and the median length of time observed for each resident was 390 days (range 1101403 days). Due to the small number of residents changing wandering status a second time, the remaining results address only the first change in status.

The mean number of observations between the first change to non-wanderer status was $4(\mathrm{SD}=2.63)$, and the mean number of days between the first switch to non-wanderer status was $252.1 \quad(\mathrm{SD}=226.1)$. The majority of wanderers who changed status retained the same level of cognitive impairment from admission to their change in status (none/borderline 90\%, mild/ moderate $=84 \%$, and severe $=77 \%$ ).

The results from the multivariate logistic regression can be seen in Table 2. Five variables were significantly 


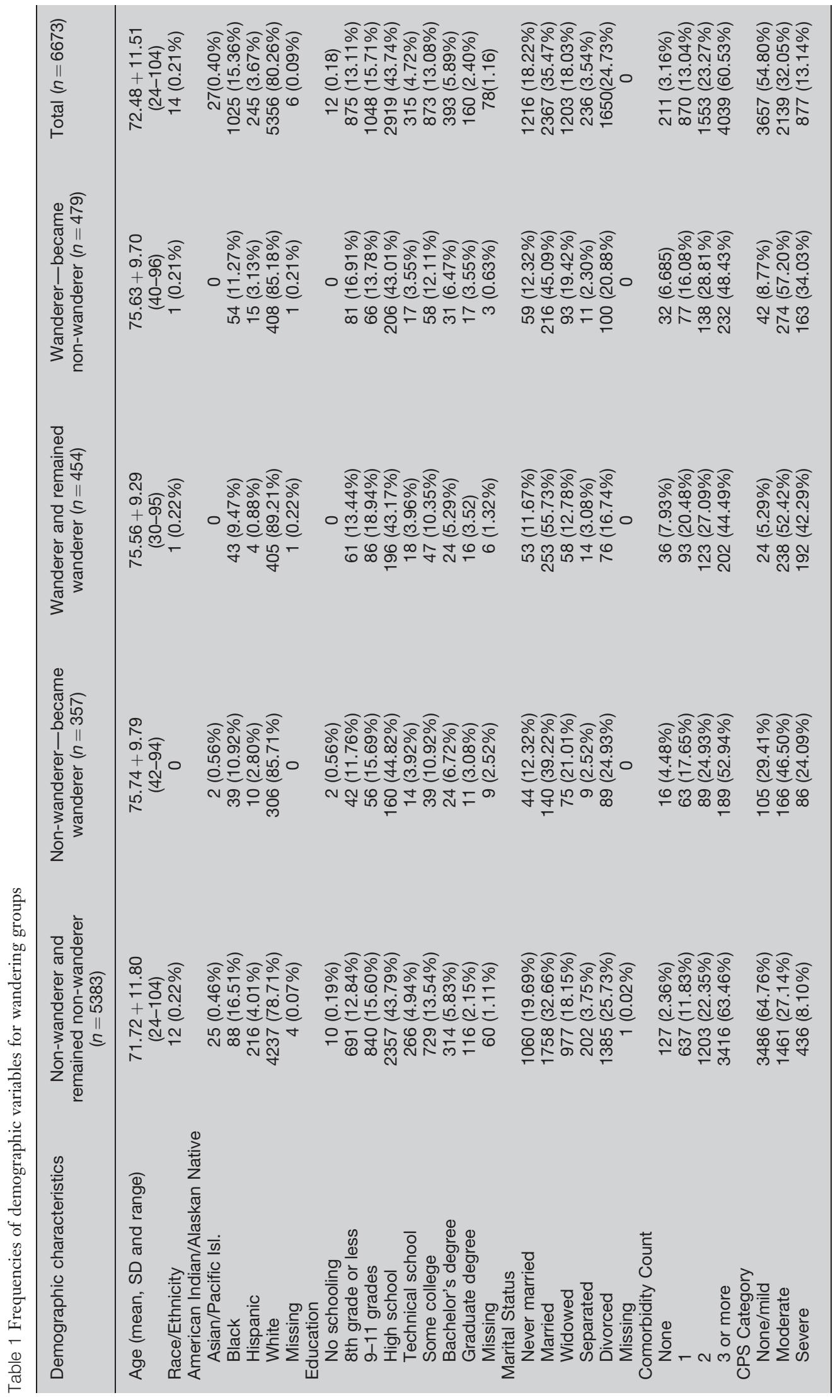


Table 2 Logistic regression comparing stable wanderers with changing status wanderers $(n=933)$

\begin{tabular}{|c|c|c|c|c|c|}
\hline Variable & OR & Adjusted OR & Standard error & $95 \% \mathrm{Cl}$ & $p$-value \\
\hline Age & 1.01 & 1.01 & 0.01 & $0.99-1.02$ & 0.764 \\
\hline \multicolumn{6}{|l|}{ Cognitive performance scale } \\
\hline None/borderline & Reference & & & & \\
\hline Mild/moderate & 0.66 & 0.65 & 0.18 & $0.38-1.13$ & 0.128 \\
\hline Severe & $0.48 * *$ & 0.48 & 0.14 & $0.27-0.87$ & 0.015 \\
\hline Socially inappropriate behavior & $0.72 *$ & 0.69 & 0.10 & $0.51-0.93$ & 0.015 \\
\hline \multicolumn{6}{|l|}{ Personal hygiene } \\
\hline No assistance & Reference & & & & \\
\hline Limited assistance & 0.62 & 0.55 & 0.15 & $0.32-0.95$ & 0.033 \\
\hline Dependent & 0.66 & 0.60 & 0.18 & $0.33-1.07$ & 0.084 \\
\hline \multicolumn{6}{|l|}{ Locomotion on unit } \\
\hline No assistance & Reference & & & & \\
\hline Limited assistance & $1.84 * * *$ & 1.97 & 0.31 & $1.45-2.68$ & $<0.001$ \\
\hline Dependent & $2.21 * *$ & 2.47 & 0.63 & $1.49-4.09$ & $<0.001$ \\
\hline \multicolumn{6}{|l|}{ Comorbidity count } \\
\hline None & Reference & & & & \\
\hline 1 & 0.93 & 0.83 & 0.24 & $0.46-1.47$ & 0.516 \\
\hline 2 & 1.26 & 1.16 & 0.32 & $0.67-2.00$ & 0.602 \\
\hline 3 or more & 1.29 & 1.14 & 0.31 & $0.67-1.93$ & 0.620 \\
\hline
\end{tabular}

$* p$-value $<0.05 ; * *<0.01 ; * * *<0.001$.

associated with change in wandering status. Those with severe cognitive impairment were less likely to change to non-wanderers than those with no or borderline cognitive impairment $(\mathrm{OR}=0.48,95 \% \mathrm{CI}$ 0.27-0.87, $p=0.015)$. Residents who exhibit socially inappropriate behavior are less likely to change to non-wanderers than those who do not exhibit these behaviors $(\mathrm{OR}=0.48$, $95 \%$ CI $0.51-0.93, p=0.015$ ). Residents who required limited assistance with personal hygiene were less likely to change to non-wanderers than those requiring no assistance $(\mathrm{OR}=0.55,95 \% \mathrm{CI} \quad 0.32-0.95, p=0.033)$, however care must be taken in interpreting this result as the variable is significant due to classical suppression. That is, requiring limited assistance with personal hygiene is not directly related to change in wandering status; however when another activity of daily living, locomotion on the unit, is included in the model the error in personal hygiene is suppressed and it improves as a predictor of wandering. Residents who required limited assistance or were dependent on others for their locomotion on the unit were more likely to change to non-wanderer status than those residents requiring no assistance $(\mathrm{OR}=1.97,95 \% \mathrm{CI} 1.45-2.68, p<0.001$ and $\mathrm{OR}=2.47,95 \% \mathrm{CI} 1.49-4.09, p<0.001)$.

\section{Non-wanderers at admission}

Of the 5740 residents ( $86 \%$ ) classified as non-wanderers at admission, 94\% remained as non-wanderers for the duration of the study or until discharge. Of the remaining residents who changed status $(n=357)$, $51 \%$ had one change of status, while $41 \%$ were nonwanderers at admission and changed to wanderers and then back to non-wanderers. In other words, 92\% changed wandering status at most twice during the observation period. The remaining $8 \%$ fluctuated in status multiple times. The mean number of observations in the data base was $5.5(\mathrm{SD}=3.4)$ and the median length of time residents were observed was 297 days (range 851403 days). As was the case with the wanderers at admission, due to the small number of residents changing wandering status a second time, the remaining results address only the first change in status.

The mean number of observations between the first status change to a wanderer was $4(\mathrm{SD}=2.65)$, and the mean number of days between the first status change to wandering was 251.3 days ( $S D=225.5)$. The majority of non-wanderers who changed status and who had mild or moderate cognitive impairment remained similarly impaired from admission to their status change $($ mild $/$ moderate $=84 \%$ and severe $=77 \%)$; however $50 \%$ of changers with none/borderline CI had a deterioration of impairment by the time that they were classified as a wanderer.

The results of the multivariate logistic regression performed on admitted non-wanderers can be seen in Table 3. Variables associated with an increased risk of status change from non-wanderer to wanderer included older age $(\mathrm{OR}=1.03,95 \% \mathrm{CI} 1.02-1.04, p<0.001)$ and cognitive impairment. Those with moderate or severe 
Table 3 Logistic regression comparing stable non-wanderers with status- changing non-wanderers $(n=5740)$

\begin{tabular}{|c|c|c|c|c|c|}
\hline & OR & Adjusted OR & Standard Error & $95 \% \mathrm{Cl}$ & $p$-Value \\
\hline Age & $1.03 * * *$ & 1.03 & 0.01 & $1.02-1.04$ & $<0.001$ \\
\hline \multicolumn{6}{|c|}{ Cognitive performance scale } \\
\hline None/borderline & Reference & & & & \\
\hline Mild/moderate & $3.77 * * *$ & 2.96 & 0.41 & $2.25-3.89$ & $<0.001$ \\
\hline Severe & $6.55 * * *$ & 5.45 & 1.07 & $3.71-7.99$ & $<0.001$ \\
\hline \multicolumn{6}{|l|}{ Socially inappropriate } \\
\hline Behavior & $3.46 * * *$ & 1.67 & 0.34 & $1.13-2.50$ & 0.011 \\
\hline Resists care & $3.11 * * *$ & 1.51 & 0.26 & $1.06-2.07$ & 0.016 \\
\hline Easily distracted & $3.72 * * *$ & 1.83 & 0.26 & $1.38-2.43$ & $<0.001$ \\
\hline \multicolumn{6}{|l|}{ Personal hygiene } \\
\hline No assistance & Reference & & & & \\
\hline Limited assistance & $1.94 * * *$ & 1.48 & 0.25 & $1.06-2.07$ & 0.021 \\
\hline Dependent & $1.98 * * *$ & 1.50 & 0.31 & $0.99-2.26$ & 0.051 \\
\hline \multicolumn{6}{|l|}{ Locomotion on unit } \\
\hline No assistance & Reference & & & & \\
\hline Limited assistance & 0.97 & 0.61 & 0.09 & $0.45-0.82$ & 0.004 \\
\hline Dependent & $0.73 *$ & 0.29 & 0.05 & $0.21-0.42$ & $<0.001$ \\
\hline \multicolumn{6}{|l|}{ Comorbidity count } \\
\hline None & Reference & & & & \\
\hline 1 & 0.78 & 0.79 & 0.24 & $0.43-1.45$ & 0.445 \\
\hline 2 & 0.59 & 0.61 & 0.18 & $0.34-1.10$ & 0.102 \\
\hline 3 or more & $0.44 * *$ & 0.49 & 0.14 & $0.28-0.87$ & 0.015 \\
\hline
\end{tabular}

$* p$-value $<0.05 ; * *<0.01 ; * * *<0.001$.

cognitive impairment were more likely to change to wanderer status when compared to those with non/ borderline cognitive impairment $(\mathrm{OR}=2.96,95 \% \mathrm{CI}$ $2.25-3.89, p<0.001$ and $\mathrm{OR}=5.45,95 \% \mathrm{CI} 3.71-7.99$, $p<0.001)$. In addition, residents exhibiting socially inappropriate behavior were more likely to change to a wanderer than those not exhibiting such signs $(\mathrm{OR}=1.67,95 \% \mathrm{CI} 1.13-2.50, p=0.011)$. Resisting care was also associated with an increased likelihood of changing to a wanderer $(\mathrm{OR}=1.51,95 \% \mathrm{CI} 1.06-2.07$, $p=0.016)$ as was the tendency to be easily distracted (OR $1.83,95 \%$ CI $1.38-2.43, p<0.001)$. Residents requiring limited assistance with personal hygiene were more likely to change to a wanderer compared to those who required no assistance $(\mathrm{OR}=1.48,95 \% \mathrm{CI} 1.06-2.07, p=0.021)$, and being dependent for assistance with personal hygiene showed a weak non-significant trend in the same direction. Two variables were associated with a decreased risk of changing wandering status. Residents requiring limited assistance or designated as dependent on the 'locomotion on unit' variable were less likely to change to a wanderer than residents requiring no assistance $(\mathrm{OR}=0.61,95 \% \mathrm{CI} \quad 0.45-0.82, p=0.004$ and $\mathrm{OR}=0.29,95 \% \mathrm{CI} 0.21-0.42, p<0.001)$. The presence of three or more comorbidities also decreased the risk of becoming a wanderer when compared to those with no comorbidities $(\mathrm{OR}=0.49$ 95\%CI $0.28-0.87$, $p=0.015)$.

\section{Discussion}

This is the first large study investigating the trajectory of wandering over an extended interval. The main results of this longitudinal study of first time $\mathrm{NH}$ admissions were that the majority (86\%) of the sample was classified as non-wanderers at admission and 94\% of these remained non-wanderers until discharge or the end of the study. Fifty-one per cent of the wanderers changed status to non-wanderers, with $6 \%$ of these residents fluctuating in status more than twice. Residents with severe cognitive impairment, who exhibited socially inappropriate behavior, or who required assistance with personal hygiene at admission were less likely to change from wandering to nonwandering; residents who were dependent for locomotion were more likely to change status to a nonwanderer. Admission variables associated with an increased risk of changing status from non-wandering to wandering included older age, greater cognitive impairment, more socially inappropriate behavior, resisting care, easy distractibility, and needing limited assistance with personal hygiene compared to no assistance. Requiring assistance with locomotion and a greater number of medical comorbidities were associated with a decreased chance of changing from non-wandering to wandering status. These results are consistent with our previous cross-sectional work 
using this VA MDS data base which found that wanderers were more likely to exhibit severe (vs. moderate) cognitive impairment, socially inappropriate behavior, resistance to care, independence in locomotion or ambulation, and dependence in activities of daily living related to basic hygiene (Schonfeld et al., 2007a).

It appears that wandering status is more likely to change from wandering to non-wandering rather than the reverse, and that wandering is a temporary phase for approximately half of those residents who are admitted as wanderers. It could be that as length of stay increases physical limitations lead to less mobility, thereby limiting one's chances of becoming a wanderer. One practical application of these findings is that NH staff should re-evaluate the necessity for ongoing wandering restrictions, which may become unnecessary with time. If a resident does change from being a non-wanderer to a wanderer, such a change may reflect either advancing dementia or some undiagnosed medical event that affects cognition but spares mobility, perhaps causing a delirium. Aggressive assessment should be instituted to assure that reversible conditions are promptly treated.

NH staff should target those who are admitted with wandering behavior, because half of these residents will continue with this behavior over an extended period of time often leading to negative outcomes associated with this behavior. Again, those who have a combination of relatively poorer cognitive skills but better mobility are the ones who are more likely to continue to wander or to become a wanderer. Such residents need closer monitoring and should be placed on units or wings considered more secure. Environmental changes and behavior modification programs may not completely eliminate such behavior, but can allow wandering to occur in a more safe and secure manner (Holmberg, 1997; Beattie et al., 2004; Cohen-Mansfield et al., 1997; Robinson et al., 2006; Schonfeld et al., 2007b).

There are a number of limitations to this study. The data were restricted to variables included in the MDS, with controversy and conflicting views regarding its reliability and validity (Arling et al., 2000; Mor et al., 2003). We used an all male veteran sample, and the results may not generalize to females or non-veterans. Wandering may have precipitated discharge from the $\mathrm{NH}$ which could have biased the results in undefined ways. We must entertain the possibility that the changes in wandering status might be due to multiple eyes observing the same patient, some trained to see one thing, and some trained to see another. The lack of a uniform system to measure wandering is problematic for this kind of research (Algase et al., 2007). Due a non- continuous observation period we cannot be certain that we captured all changes correctly. It is unfortunate that analyses that could have incorporated the time series nature of this data were problematic. Perhaps most importantly, we did not have data on how environmental stressors or wandering-specific interventions could be related to change in wandering status. We also did not have data on reasons for admission for the wanderers versus the non-wanderers. It could be that those who wander on admission represent a challenging group of cognitively impaired individuals with dementia who are admitted because of the salience and/or extended period of this behavior in the community which could no longer be controlled by caregivers.

Although all wandering is not problematic and indeed some wandering can be therapeutic by increasing physical fitness and maintaining activity (Cohen-Mansfield et al., 1991; Yao and Algase, 2006), more studies delineating safe from unsafe wandering behavior need to be conducted. Future research should explore in detail the specific biological, psychiatric, psychological, and social precursors of new onset wandering behavior in $\mathrm{NH}$ settings. It is time for algorithms to be developed to 'red flag' those residents who wander upon admission and to identify those who are at risk for developing dangerous wandering behaviors. Residents with defined characteristics may need staff to be aware of the threat of wandering so that they are able to react quickly and implement programs to reduce harmful consequences, such as falls or elopement. Evidence based validation of diverse nursing, psychological, psychopharmacological, and technological treatments will permit selective implementation of interventions upon admission in various long-term care settings. Such preventative programs may increase the number of wanderers who switch to non-wanderers, and decrease the number of nonwanderers who become wanderers.

\section{Key Points}

- Most VA NH residents are non-wanderers at admission and remain non-wanderers.

- Those NH residents who are older, have greater cognitive impairment, more problematic behaviour, and need less help with personal hygiene are at higher risk for becoming a wanderer.

- A NH resident's change to wandering status may reflect an undetected medical event that affects cognition but not mobility. 


\section{Conflict of interest}

None known.

\section{Author contributions}

Bellinda King-Kallimanis: Study concept and design; analysis and interpretation of data, and preparation of manuscript.

Lawrence Schonfeld: Study concept and design; analysis and interpretation of data, and preparation of manuscript.

Victor Molinari: Study concept and design; analysis and interpretation of data, and preparation of manuscript.

Donna Algase: Study concept and design; analysis and interpretation of data, and preparation of manuscript.

Lisa Brown: Study concept and design; analysis and interpretation of data, and preparation of manuscript.

Darlene Davis: Study concept and design; acquisition of data.

William Kearns: Study concept and design; analysis and interpretation of data, and preparation of manuscript.

Dennis Werner: Study concept and design; acquisition of data.

Elizabeth Beattie: Study concept and design.

Audrey Nelson: Study concept and design; acquisition of data; analysis and interpretation of data, and preparation of manuscript.

\section{References}

Algase DL. 1992. Cognitive discriminants of wandering among nursing home residents. Nurs Res 41: 78-81.

Algase DL. 1998. Wandering. In: Comprehensive Clinical Psychology, Edelstein B (ed.) Pergamon: Geropsychiatry. London; 7: p. 371-412.

Algase DL. 1999. Wandering in dementia. Annual Rev Nurs Res 17: 185-217.

Algase DL, Beel-Bates C, Beattie ERA. 2003. Wandering in long-term care. Ann Long Term Care 11: 33-39.

Algase DL, Moore DH, Vandeweerd C, et al. 2007. Mapping the maze of terms and definitions in dementia-related wandering. Aging Ment Health 11: 686-698.

Algase D, Struble L. 1992. Wandering: what, why, and how? In Geriatric Mental Health Nursing: Current and Future Challenges, Buckwalter K (ed.). Slack, Inc: Thorofare, NJ; pp. 61-74.

Altus DE, Mathews RM, Xaverius PK, et al. 2000. Evaluating an electronic monitoring system for people who wander. Amer J of Alzheimer's Dis 15: 121-125.

Arling G, Kane RL, Lewis T. 2000. Future development of nursing home quality indicators. Gerontologist 45: 147-156.

Beattie E, Algase DL, Song J. 2004. Keeping wandering nursing home residents at the table: improving food intake using a behavioural communication intervention. Ageing Ment Health 8: 109-116.
Belanger HG, King-Kallimanis B, Nelson AL, et al. 2008. Characterizing wandering behaviors in persons with traumatic brain injury residing in VA nursing homes. Arch Phys Med \& Rehab 89: 244-250.

Burns AJR, Jacoby R, Levy R. 1990. Psychiatric phenomena in Alzheimer's disease. IV: disorders of behaviour. Brit J Psychiatry 157: 86-94.

Burton LC, German PS, Rovner BW, et al. 1992. Mental illness and the use of restraints in nursing homes. Gerontologist 32: 164-170.

Cancro R. 1968. Elopements from the C.F. Menninger Memorial Hospital. Bull Menninger Clin 32: 228-238.

Cesari M, Landi F, Torre S, et al. 2002. Prevalence and risk factors for falls in an older community-dwelling population. J Gerontol A Biol Sci Med Sci 57: M722-726

Cohen-Mansfield J, Werner P, Culpepper WJ, Barkley D. 1997. Evaluation of an inservice training program on dementia and wandering. J Gerontolog Nurs 23: 40-47.

Cohen-Mansfield J, Werner P, Marx MS, et al. 1991. Two studies of pacing in the nursing home. J Gerontol 46: M77-M83.

Colombo M, Vitali S, Cairatie M, et al. 2001. Wanderers: features, findings, issues. Arch Gerontolo Geriatr 7: 99-106.

Colon-Emeric CS, Datta SK, Matchar DB. 2003. An economic analysis of external hip protector use in ambulatory nursing facility residents. Age Ageing 32: 47-52.

Cooper JK, Mungas D. 1993. Risk factor and behavioral differences between vascular and Alzheimer's dementias: the pathway to end-stage disease. J Geriatr Psychiatry Neurol 6: 29-33.

Cumming J, Cumming E, Titus J, et al. 1982. The episodic nature of behavioral disturbances among residents of facilities for the aged. Can J Public Health 73: 319-322.

Dawson P, Reid DW. 1987. Behavioral dimensions of patients at risk of wandering. Gerontologist 27: 104-107.

Desai AK, Grossberg GT. 2001. Recognition and management of behavioral disturbances in dementia. Prim Care Companion J Clin Psychiatry 3: 93109.

Fompa-Loy J. 1988. Wandering: causes, consequences, and care. J Psychosocial Nurs \& Med Health Services 26: 8-18.

Foxwell LG. 1994. Elopement-exposure and control. J Long-term Care Admin 21: 8-12.

Health Care Financing Administration Medicare and Medicaid. 1989. Requirements for long term care facilities. Federal Register 54: 5316-5336.

Heard K, Watson TS. 1999. Reducing wandering by persons with dementia using differential reinforcement. J Appl Behav Anal 32: 381-384.

Heeren O, Borin L, Raskin A, et al. 2003. Association of depression with agitation in elderly nursing home residents. J Geriatr Psychiatry Neurol 16: 4-7.

Hermans DG, Htay UH, McShane R. 2007. Non-pharmacological interventions for wandering of people with dementia in the domestic setting. Cochrane Database Syst Rev 1: CD005994.

Holmberg SK. 1997. Evaluation of a clinical intervention for wanderers on a geriatric nursing unit. Arch Psychiatr Nurs 11: 21-28.

Hope T, Tiling KM, Gedling K, et al. 1994. The structure of wandering in dementia. Intern J Geriatr Psychiatry 9: 149-155.

Hope T, Keene J, McShane RH, et al. 2001. Wandering in dementia: a longitudinal study. Int Psychogeriatr 13: 137-147.

Kiely DK, Kiel DP, Burrows AB, et al. 1998. Identifying nursing home residents at risk for falling. J Am Geriatr Soc 46: 551-555.

Kiely DK, Morris JN, Algase DL. 2000. Resident characteristics associated with wandering in nursing homes. Int J Geriatr Psychiatry 15: 1013-1020.

Klein DA, Steinberg M, Galik E, et al. 1999. Wandering behavior in community-residing persons with dementia. Int J Geriatr Psychiatry 14: 272-279.

Kopetz S, Steele CD, Brandt J, et al. 2000. Characteristics and outcomes of dementia residents in an assisted living facility. Int J Geriatr Psychiatry 15: 586-593.

Lam D, Sewell M, Bell G, et al. 1989. Who needs psychogeriatric continuing care? Int J Ger Psychiatr 4: 109-114.

Moak GS. 1990. Characteristics of demented and nondemented geriatric admissions to a state hospital. Hosp Community Psychiatry 41: 799-801.

Molinari V, King-Kallimanis B, Volicer L, et al. 2008. Wandering behavior in nursing home residents with psychiatric diagnoses. Int $J$ Geriatr Psychiatr 23: 748-753. 
Mor V, Angelelli J, Jones R, et al. 2003. Inter-rater reliability of nursing home quality indicators in the U.S. BMC Health Serv Res 3: 20-55.

Nagaratnam N, Lewis-Jones M, Scott D, et al. 1998. Behavioral and psychiatric manifestations in dementia patients in a community: caregiver burden and outcome. Alzheimer Dis Assoc Disord 12: 330-334.

Rader J. 1987. A comprehensive staff approach to problem wandering. Gerontologist 27: 756-760.

Rheaume Y, Riley ME, Volicer L. 1987. Meeting nutritional needs of Alzheimer patients who pace constantly. J Nutr Elder 7: 43-52.

Robinson L, Hutchings D, Corner L, et al. 2006. A systematic literature review of the effectiveness of non-pharmacological interventions to prevent wandering in dementia and evaluation of the ethical implications and acceptability of their use. Health Technol Assess 10: 1-124.

Rockwood K, Stolee P, Brahim A. 1991. Outcomes of admission to a psychogeriatric service. Can J Psychiatry 36: 275-279.

Rodriguez J. 1993. Resident falls and elopement: cost and controls. Nursing Homes 4: 16-17.

Rovner BW, Kafonek S, Filipp L, et al. 1986. Prevalence of mental illness in a community nursing home. Am J Psychiatry 143: 1446-1449.

Schonfeld L, King-Kallimanis B, Brown L, et al. 2007a. Wanderers with cognitive impairment in VA nursing home care units. J Amer Geriatr Soc 55: 692-699.
Schonfeld L, Brown L, Molinari VA. 2007b. Behavior management of wandering behavior: staff and caregiver training issues. In Safe and Ethical Approaches for Wandering Behaviors: A Practice Guide, Nelson A, Algase D (eds). Springer: New York; 195-213.

Snyder LH, Rupprecht P, Pyrek J, et al. 1978a. Wandering. Gerontologist 18 272-280.

Soverini S, Borghesi E. 1968. On a strange case of wandering in an arteriosclerotic demented patient. J Gerontol 16: 846-851.

Stokes G. 1986. Wandering, Common Problems With the Elderly Confused. Winslow Press: Bicester, UK.

Teri L, Larson EB, Reifler BV. 1988. Behavioral disturbances in dementia of the Alzheimer's type. J Amer Geriatric Soc 36: 1-6.

Thomas DW. 1997. Understanding the wandering patient: a continuity of personality perspective. J Gerontol Nurs 23: 16-24.

Vieweg V, Blair CE, Tucker R, et al. 1995. Factors precluding patients' discharge to the community: a geropsychiatric hospital survey. Virginia Med Quarterly 122: 275-278.

Ward S, Opie J, O'Connor DW. 2003. Family carers' responses to behavioural and psychological symptoms of dementia. Int J Geriatr Psychiatry 18: 1007-1012.

Yao L, Algase D. 2006. Environmental ambiance as a new window on wandering. Western J Nurs Res 28: 89-104. 